\title{
Surgical Treatment of Atrial Fibrillation with Electhocautery during Mitral Valve Replacement
}

\author{
Rampada Sarker ${ }^{1}$, Manoz Kumar Sarker ${ }^{1}$, Md. Ataher Ali $^{2}$, Abdul KhalelequeBeg ${ }^{3}$ \\ ${ }^{1}$ Departmentof Cardiac Surgery, NICVD, Dhaka, ${ }^{2}$ Department of Electrophysiology, NICVD, Dhaka, \\ ${ }^{3}$ Department of Anesthesiology, NICVD,Dhaka
}

Key Words:
Atrial fibrillation,
Mitral valve
replacement,
Thromboembolism.

\begin{abstract}
:
Background: The Maze procedure is the surgical treatment that can alleviate the three complications of atrial fibrillation-tachycardia, thrombo-embolism and hemodynamic compromise. We attempted ablation of atrial fibrillation with monopolar eletrocautery.Our objective was to evaluate the results of surgical treatment of atrial fibrillation by ablation of the left atrial wallaround the pulmonary veins with conventional electrocautery during mitral valve replacement.

Methods:This retrospective observational study was carried out in the Department of Cardiac Surgery, National Institute of cardiovascular diseases, Dhaka, Bangladesh,from January 2014 to February 2016. Ablation of AF with monopolar electrocautery was done during mitral valve replacement. Recurrence of atrial fibrillation, any new arrhythmia, complete heart block, bleeding and perforation was noted during the operation and in postoperative period. Patients were followed up upto three months after the surgery.

Results: All the Patients were free from atrial fibrillation after the procedure. At discharge $100 \%$, after I month $96.2 \%$ and after 3 months $92.3 \%$ patient were free from atrial fibrillation. No patients developed complete heart block requiring pace maker and there was no incidence of atrial perforation at the sites of ablation.

Conclusion: The surgical treatment of the atrial fibrillation with elcetrocautery during mitral valve replacement is able to reverse this arrhythmia in a significant number of patients during short term follow-up without any complication.
\end{abstract}

(Cardiovasc. j. 2016; 9(1): 9-12)

\section{Introduction :}

Atrial fibrillation (AF) is the most common supraventricular arrhythmia to cause thromboembolic accident and heart failure in mitral valvular diseases. ${ }^{1}$ The prevalence of AF in patients scheduled for a mitral valve procedure is still between 30 and $84 \%{ }^{2,3}$ The Framinghan study has shown that incidence of stroke is higher in patients with AF. ${ }^{4}$ Surgical treatment became evident from 1991 on when Cox et al. by means of experimental studies and their knowledge of $\mathrm{AF}$ electrophysiology published a new technique the "Labyrinth operation" the Maze procedure, described for isolated treatment of AF. ${ }^{5-8}$ This technique consists in multiple incisions and sutures in the atria, forming block lines for the macroentrant circuits, which were considered to be one of the AF pathophysiological mechanism. ${ }^{9}$ An alternative proposed in the last few years was the incisions and sutures by the ablation of atrial tissue with sources of energy such as cryoablation, radiofrequency, microwaves ultrasound and electrocautery. ${ }^{10}$ In order to perform transmural lesions, besides a specific approach of critical areas for AF outburst and perpetuation (ectopic focuses are present in the pulmonary vein Ostia). ${ }^{11}$ The combination of a Maze procedure characterized by an extensive use of right and left atral incision has proven effective in restoring sinus rhythm but it requires a considerable prolongation of cardiopulmonary bypass(CPB) and aortic cross clamp time(X-CT) when performed in combination with other open heart surgery. Moreover even when sinus rhythm is restored after combined valve surgery and Maze procedure recovery of atrial function is below $80 \% .{ }^{12,13}$ We started to practice the surgical treatment of AF by ablation of the left atrium around the pulmonary veins with electrocautery during mitral valve replacement at the beginning of 2014. This retrospective study

Address of Correspondence: Prof. Rampada Sarker, Department of Cardiac Surgery, National Institute of Cardiovascular Diseases and Hospital, Dhaka, Bangladesh. Email: rampada.heartsurgeon@gmail.com 
aims to observe whether this procedure was able to reverse $\mathrm{AF}$ and to see the incidence of recurrence of this arrhythmia during short term follow up.

\section{Methods:}

This retrospective observational study was carried out in the department of cardiac surgery. National Institute of cardiovascular diseases (NICVD) and Hospital, Dhaka, Bangladesh between January 2014 to February 2016 by the permission of academic council of the institutes among the patients who underwent mitral valve replacement along with ablation of AF with monopolar electrocautery within that period. Data were collected from records of operation theatre (OT). Intensive care unit (ICU), wards and follow-up files of our cardiac surgery unit.

\section{Surgical technique:}

The chest was opened with median longitudinal sternotomy CPB was established with aortic wand bi-caval cannulation. The heart was arrested by ante grade cold $\left(4^{0} \mathrm{C}\right)$ blood cardioplegic solution under moderate hypothermia. The left atrium was adequately sucked and dried up after atriotomy. The monopolar electrocautery was set-up with power adjustment between 25 to 30 watts by seeing depth of burn on the endocardium near atriotomy margin. Lines of ablation were created around the four pulmonary veins $5 \mathrm{~mm}$ from the margin
(Figure-1) in order to avoid cicatrical stenosis of the veins. A careful washing of the left atrial chamber was performed with slightly wet gauge to remove the carbonization products to avoid systemic embolism. The ablation device consisted of energy generator of electro cauterization model EXCELL NHP 350/D, manufactured by ALSA, Italy. Then mitral valve replacement (MVR) was completed. The patients were weaned from CPB and chest was closed. At the end of surgery patients were transferred to ICU where continuous ECG monitoring was done. Any recurrence of AF, other arrhythmia, complete Heart block (CHB) and any excessive bleeding were noted in the ICU flow chart.

Postoperative follow-up : ECG was performed at discharge, at 1 months, and 3 months follow-up, which were kept in register of our cardiac surgery unit.

\section{Results:}

Total 26 patients were undergone elcetrocautery ablation with MVR; mean age of the pt was 34.65 years , $7(26.9 \%)$ were male and $19(73.1 \%)$ were female and mean body weight was $50.08 \mathrm{~kg}$. After the surgery all patients were free from AF at entry into intensive care unit (ICU). At discharge 26 patients(100\%), at 1 month 25 patients $(96.2 \%)$, and at 3 month follow up 24 patients $(92.3 \%)$ were free from AF (Table-II and Figure -2) .

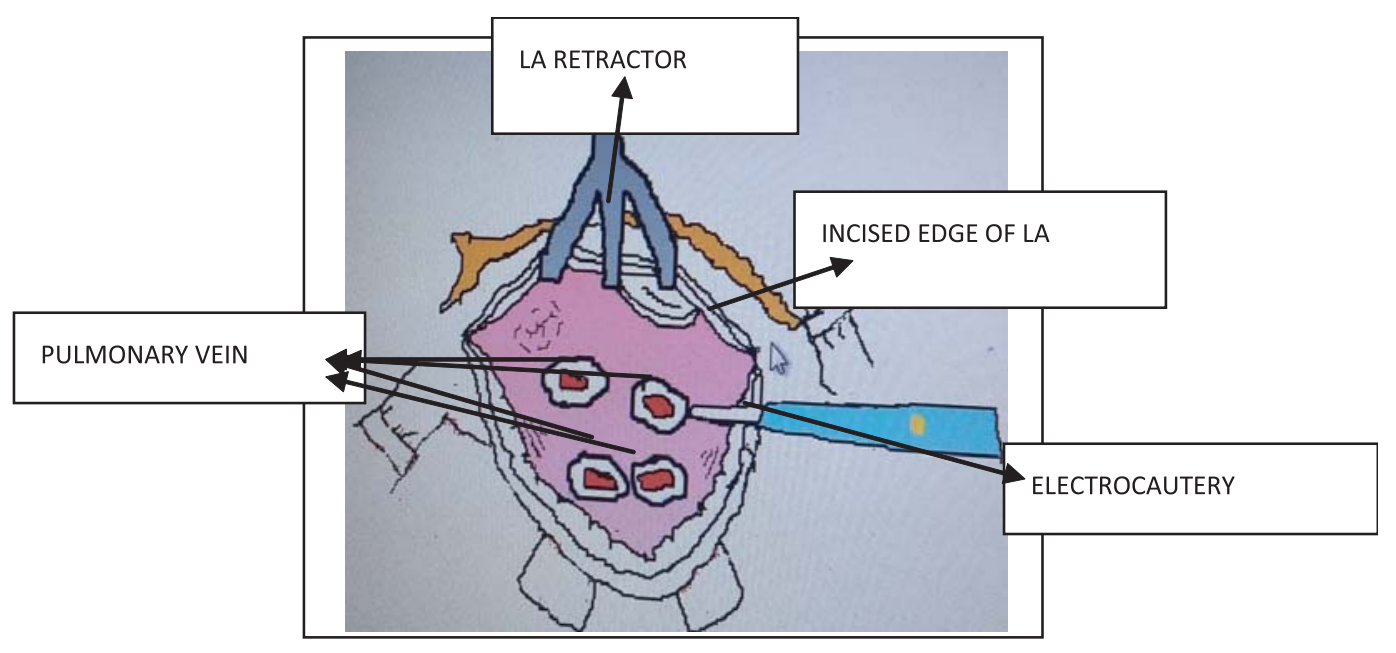

Fig-1: Site of electrocautery ablation in left atrium. 
Table-I

Outcome of the procedure at different time intervals among the study population $(n=26)$.

\begin{tabular}{|c|c|c|c|c|c|c|c|c|}
\hline & \multicolumn{2}{|c|}{ At entry in ICU } & \multicolumn{2}{|c|}{ At 7th POD } & \multicolumn{2}{|c|}{ At I Month } & \multicolumn{2}{|c|}{ At 3 Months } \\
\hline & Frequency & $\overline{\text { Percent }}$ & Frequency & $\overline{\text { Percent }}$ & Frequency & Percent & Frequency & $\overline{\text { Percent }}$ \\
\hline Free from AF & 26 & 100 & 26 & 100 & 25 & 96.2 & 24 & 92.30 \\
\hline Recurrence of AF & 0 & 0 & 0 & 0 & 1 & 3.8 & 2 & 7.69 \\
\hline Total & 26 & 100 & 26 & 100 & 26 & 100.0 & 26 & 100 \\
\hline
\end{tabular}

\section{Discussion :}

The results of this study was compared to those of other authors. Gomes Junior et al ${ }^{1}$ under took a study with elcetrocautery ablation of AF during mitral valve surgery and showed that $73.9 \%$ of patients were free from AF after 6 months. But we succeeded to collect only three month follow up data retrospectively when $92 \%$ patients were free of AF. Sueda and colleagues addressed only left atrium for AF treatment and successfully reached $100 \%$ of regular rhythm after surgery and $78 \%$ at six months. ${ }^{14}$ Kalil and associates published a study in which they performed only isolation of pulmonary vein Ostia reaching $86 \%$ of sinus rhythm at 1 month follow-up. ${ }^{15}$ In our study at 1 month follow up $96 \%$ patients were free from AF. Inamdar et al. in an approach only to the left atrium using electrocautery, observed a high of AF recurrence in first month postoperatively possibly due to inadequate ablation of atrial tissue producing incomplete lines. ${ }^{16}$ Additionally, it was hypothesized that three to six months would be needed to complete cicatrization of the ablation lines to achieve an efficient stimuli block. Recurrence of $\mathrm{AF}$ in first week after ablation does not mean procedural failure, but $100 \%$ of our patients were free from recurrence of $\mathrm{AF}$ at the end of first week. Lam et al ${ }^{17}$ showed that the power setting and the tissue contact time exerts a direct effect on in the depth of atrial lesions. At the power setting lower than 25 watts, the destruction is low. The power should be between 25 to 30 watts, contact time should be 1 to 3 second/ $\mathrm{cm}$. Our approach was similar to their suggestions of power setup and contact time. Surgeries for AF can pose inherent complications to the surgical procedures, such as lesion of circumflex branch of left coronary artery, rupture of left atrial wall and esophageal perforation causing atrio-esohageal fistula, they are severe but very rare complications. ${ }^{10}$ In our patients there were no such complication. Durunkan et al. showed in a study that electrocautery-ablation seemed to have comparable results with radiofrequency- ablation after two techniques of ablation for AF. ${ }^{18}$

Surgical ablation seems to play an increasing role for several reasons: high success rate, surgeon's direct view making the ablation safer and faster and simplicity of the technique, which does not prolong surgery times, makes it possible to be performed by every surgeon. ${ }^{1}$

Our study was retrospective with only 26 patients and follow-up was three months. A prospective, large randomized, multi-centre trial with long term follow-up is necessary to comment on the results of electrocautery ablation on surgical treatment of $\mathrm{AF}$.

\section{Conclusion:}

This study showed that the surgical treatment of atrial fibrillation with electro cautery during mitral valve replacement surgery, was capable reversing atrial fibrillation during short term follow-up without any mortality and morbidity, more over this procedure is accessible with no need of special and expensive equipment.

\section{Acknowledgement:}

We thank to OT in-charge Farida Yasmin, and to ICU in-charge Kabita Rani Podder for their cooperation in collecting the data for this study.

\section{Conflict of Interest - None.}

\section{References:}

1. Gomes Jr. JF, Pontes JCDV, Gomes OM, Duarte JJ, Gardenal N, Dias AMSAS, et al. Surgical treatment of chronic atrial fibrillation with conventional electrocautery in mitral valve surgery. Rew Bras Cir Cardiovasc 2008; 23(3): 365-371. 
2. Chua LY, Schaff HV, Orszulak TA, Morris JJ. Outcome of mitral valve repair in patients with preoperative atrial fibrillation. I Thorac Cardiovasc Surg 1994; 107: 408-415.

3. Hirosawa K, Sekiguchi M, KasA,nuki H. Natural history of atrial fibrillation. Heart Vessel 1987: 14-23.

4. Wolf PA, Abbott RD. Kannel WB. Atrial Fibrillation as an independent risk factor for stroke: The Framingham study. Stroke 1991; 22 (8): 983-988.

5. Cox JL, Schuessler RB, Boineau JP. The surgical treatment of atrial fibrillation I. Summary of the current concepts of the mechanism of atrial flutter and fibrillation. J Thorac Cardivasc Surg 1991; 101(3): 402-405.

6. Cox JL, Canavan TE, Schuessler RB, Cain ME, Lindsay $\mathrm{BD}$, Stone C, et al. The surgical treatment of atrial fibrillation II. Intraoperative electrophysilogic mapping and description of electophysiologic basis of atrial flutter and atrial fibrillation. J Thorac Cardivasc Surg 1991; 101(3): 406-426.

7. Cox JL, Schuessler RB, D'Agostino HJ Jr, Stone CM, Chang BC, Cain ME, et al. The surgical treatment of atrial fibrillationIII. Development of a definitive surgical procedure. J Thorac Cardivasc Surg 1991; 101(4): 569583.

8. Cox JL, The surgical treatment of atrial fibrillationIV. surgical technique. J Thorac Cardivasc Surg 1991; 101(4); 584-592.

9. Moe GK. On the multiple wavelet hypothesis of atrial fibrillation. Arch Int Pharmacodyn Ther 1962; 140: 182183.

10. Abreu Filho CAC, Lisboa LAF, Dallan LAO Oliveira SA. Treatments cirugico fibrilacao atrial. Rev Bras Cir Cardiovasc, 2005; 20(2):167-173.
11. Haissaguerre M, Jais P, Shah DC, Takahashi A, Hocini M, Quiniou G, et al.Spontaneous initiation ofatrial fibrillation by ectopic beats originating in the pulmonary veins. N Engl J Med 1998; 339(10): 659-666.

12. Kosakai Y, Kawaguchi AT, Isobe F, Sasako Y, Nakano K, Eishi K, et al. Modified Maze procedure for patients with atrial fibrillation undergoing simultaneous open heart surgery. Circulation 1995; 92(suppl II) : 359-364.

13. Kawaguchi AT, Kosaki Y, Sasako Y, Eishi K, kiyoharu N, Kowashima Y. Risk and benefits of combined maze procedure for atrial fibrillation associated with organic heart disease $J$ Am Coll Cardiol 1996; 28 : 985-990.

14. Sueda T, Nagata H, Orrhashi k, Mortia S, Okada K, Sueshiro M, et al. Efficacy of a simple left atrial procedure for chronic atrial fibrillation in mitral valve operations. Ann Thorac Surg 1997; 63(4): 1070-1075.

15. Kalil RAK, Lima GG, Absahao R, Sturmer ML, Albrecht A, Moreno P, et al. Technica cirugical simplificada pode ser eficaz no treatments da fibrilacao atrial eronica secundaria a lesao valver mitral. Rev Bras Cir Cardiovasc 2000; 15 (2): 129-135.

16. Inamdar A, Reddy $\mathrm{P}$ Inamdar S, Gaikwad V. Electrocautery Maze in chronic atrial fibrillation. an early experience. IJTCVS 2005; 21 (4).9-14.

17. Lam BK, Boodhwani M, Veint JP, Henry PJ, Mesana TG. Surgical treatment of atrial fibrillation with diathermy; an in vitro study. Eur J Cardiothorac Surg 2005;27(3):456-461.

18. Durukan AB, Gurbuz HA, Tablasoglu M, Elif D, Salman N, Serter FT, et al. Surgery for atrial fibrillation. radiofrequency or electrocantery. TGKD 2012; 16 (4): 123-129. 